\title{
IPI0-CDR3 Reduces The Viability And Induces The Apoptosis Of Ovarian Cancer Cells By Down-Regulating The Expression Of Bcl-2 And Caspase 3
}

This article was published in the following Dove Press journal: OncoTargets and Therapy

\author{
Qi Chen ${ }^{1, *}$ \\ Quan $\mathrm{He}^{1}$ \\ Lingling Zhuang ${ }^{1}, *$ \\ Kunya Wang ${ }^{2}$ \\ Chunhua Yin $^{2}$ \\ Linsheng $\mathrm{He} \mathbb{D}^{1}$ \\ 'Department of Obstetrics and \\ Gynecology, The First Affiliated Hospital \\ of Nanchang University, Nanchang, Jiangxi \\ 330006, People's Republic of China; \\ ${ }^{2}$ Department of Obstetrics and \\ Gynecology, Jiangxi Provincial People's \\ Hospital, Nanchang, Jiangxi 330006, \\ People's Republic of China \\ *These authors contributed equally to \\ this work
}

\begin{abstract}
Purpose: This study aimed to explore the effects of interferon- $\gamma$ inducible protein 10 (IP10) and complementarity-determining region 3 (CDR3) of $\mathrm{T}$ cells receptor on ovarian cancer cells and the involved mechanisms.
\end{abstract}

Methods: IP10 and CDR3 were linked with single-chain antibody (scfv) and exotoxin gene muton of Pseudomonas aeruginosa (PE40) to construct IP10-CDR3scfv and IP10-CDR3PE40scfv. Then, we constructed pcDNA3.1-IP10-CDR3scfv and pcDNA3.1-IP10-CDR3PE40scfv plasmids which were proved by HindIII/EcoRI digestion. SKOV3 cells and HOSEpiC cells were incubated with fluorescein isothiocyanate (FITC) labeled IP10-CDR3scfv and IP10CDR3-PE40scfv proteins and protein levels were examined by flow cytometry. After gene transfection, SKOV3 cells were divided into four groups: Control, pcDNA3.1(+) negative control (NC) (pcDNA3.1(+) NC transfection), IP10-CDR3scfv (IP10-CDR3scfv transfection) and IP10CDR3-PE40scfv (IP10-CDR3-PE40scfv transfection). Levels of IP10, CDR3, Caspase-3, cleaved Caspase- 3 and Bcl-2 were determined by RT-PCR and Western blot. Cell viability and apoptosis were investigated by CCK-8 assay and Annexin V-FITC/PI assay, respectively.

Results: The levels of FITC-labeled IP10-CDR3scfv and IP10-CDR3-PE40scfv proteins in the SKOV3+IP10-CDR3scfv group and the SKOV3+IP10-CDR3-PE40scfv group were remarkably higher than that in the SKOV3 group $(\mathrm{P}<0.05)$. So was the HOSEpiC related groups. There was no obvious difference in the levels of IP10, CDR3, Caspase-3, cleaved Caspase-3 and Bcl-2 between the control group and the pcDNA3.1(+) NC group. However, compared with the control group, the levels of Caspase-3 and Bcl-2 were reduced notably and the levels of IP10, CDR3 and cleaved Caspase-3 were elevated sharply in the IP10CDR3scfv and IP10-CDR3-PE40scfv groups $(\mathrm{P}<0.05)$. The control group and the pcDNA3.1 $(+) \mathrm{NC}$ group demonstrated similar cell viability and apoptosis. However, compared with the control group, cell viability in the IP10-CDR3scfv and IP10-CDR3-PE40scfv groups decreased significantly and cell apoptosis increased $(\mathrm{P}<0.05)$.

Conclusion: IP10-CDR3 could reduce the viability and induce the apoptosis of ovarian cancer cells by down-regulating the expression of Bcl-2 and Caspase-3.

Keywords: ovarian cancer, IP10, CDR3, cell apoptosis, Bcl-2, Caspase-3

\section{Introduction}

Ovarian cancer is a common female malignant tumor with concealed symptoms which make it difficult to be discovered. Moreover, drug resistance to chemotherapy and delayed operation often cause unsatisfactory therapeutic effect. ${ }^{1-3}$ There are estimated
Correspondence: Linsheng $\mathrm{He}$ Department of Obstetrics and Gynecology, The First Affiliated Hospital of Nanchang University, Yongwaizheng Street 17, Donghu District, Nanchang, Jiangxi 330006, People's Republic of China Tel/Fax +8679188623153 Email whlsIsI26@I63.com 
295,414 new ovarian cancer cases and 184,799 ovarian cancer deaths worldwide in $2018 .^{4}$ Therefore, many strategies should be developed to treat ovarian cancer.

Immunotherapy can recognize and kill cancer cells effectively by motivating and enhancing immune function of the body. Effective immune response is of importance to suppress the immune escape of tumors. T cells are main effector cells of immune response. They are mainly activated by T cells receptor (TCR) and synergistic signals. ${ }^{5-7}$ TCR is a heterodimer mainly formed by $\alpha \beta$ or $\gamma \delta$ polypeptide chains through disulfide linkage. Thereinto, $\alpha \beta$ accounts for a high proportion. Gene fragments of $\alpha$ and $\beta$ chains of TCR are easily rearranged to form highly variable region which is known as complementarity-determining region 3 (CDR3). Luo et al sequenced CDR3 gene, identified the high affinity part of TCR molecular sequence and provided basis for $\mathrm{T}$ cell immunotherapy for ovarian cancer. $^{8}$

Interferon- $\gamma$ (IFN- $\gamma$ ) is a cytokine that is critical for innate and adaptive immunity. The immunostimulatory and immunomodulatory effects of IFN- $\gamma$ make it important in immune system. IFN- $\gamma$ inducible protein 10 (IP10) is a kind of CXC chemokine induced by IFN- $\gamma$. IP10 can act as a synergistic factor to promote $\mathrm{T}$ cell activation and break down the immune tolerance of tumors. ${ }^{9}$ It can enhance the chemotaxis and activation of monocyte macrophages, $\mathrm{T}$ cells and B cells, subsequently promoting the secretion of various cytokines to inhibit tumor growth. ${ }^{9-12}$ It plays an important role in many diseases such as cancer, viral hepatitis, graft rejection and tuberculosis. ${ }^{10-13}$

Therefore, in this study, IP10 and CDR3 were linked with single-chain antibody (scfv) and exotoxin gene muton of Pseudomonas aeruginosa (PE40) to construct novel immune cell elements IP10-CDR3scfv and IP10-CDR3PE40scfv through genetic engineering technology. The purpose of adding PE40 to the scfv was to achieve targeted treatment of cancer cells. Furthermore, we explored the effects of IP10-CDR3 on the growth and apoptosis of ovarian cancer cells and the involved mechanisms.

\section{Materials And Methods Materials And Cells}

CCK-8 kit was bought from Keygen Biotech (Jiangsu, China). Trizon reagent, Ultrapure RNA extraction kit, HiFiScript cDNA synthesis kit and UltraSYBR Mixture were purchased from CWBIO (Beijing, China). Annexin V-fluorescein isothiocyanate (FITC)/propidium iodide (PI) apoptosis kit was obtained from MultiSciences (Lianke) Biotech (Zhejiang, China). Polyvinylidene fluoride (PVDF) membrane was bought from Millipore (Danvers, MA, USA). Mouse antiglyceraldehyde-3-phosphate dehydrogenase (GAPDH) monoclonal antibody (TA-08, 1:2000), peroxidase-conjugated goat anti-mouse $\operatorname{IgG}(\mathrm{H}+\mathrm{L})(\mathrm{ZB}-2305,1: 2000)$ and peroxidase-conjugated goat anti-rabbit $\operatorname{IgG}(\mathrm{H}+\mathrm{L})$ (ZB-2301, 1:2000) were purchased from ZSGB-BIO (Beijing, China). Rabbit anti-Bcl-2 monoclonal antibody (ab32124, 1:1000), mouse anti-Caspase-3 monoclonal antibody (ab13585, 1:1000) and rabbit anti-cleaved Caspase-3 polyclonal antibody (ab2302, 1:500) were obtained from Abcam (Cambridge, MA, USA). FITC quick labeling kit was gotten from Biodragon Immunotechnologies (Beijing, China). Endofree plasmid mini kit II was bought from Omega Bio-tek (Norcross, GA, USA). Opti-MEM was purchased from Gibco (Grand Island, NY, USA). Lipofectamine 3000 reagent was obtained from Invitrogen (Carlsbad, CA, USA).

Human ovarian cancer cell line SKOV3 was obtained from the Type Culture Collection of the Chinese Academy of Sciences (Shanghai, China) and cultured in McCoy's 5A medium (Keygen Biotech, Jiangsu, China) supplemented with $10 \%(\mathrm{v} / \mathrm{v})$ fetal bovine serum (Hyclone, Logan, UT, USA). Human ovarian epithelial cell line HOSEpiC was gotten from BeNa Culture Collection (Beijing, China) and cultured in RPMI-1640 medium (Keygen Biotech, Jiangsu, China) supplemented with $10 \%(\mathrm{v} / \mathrm{v})$ fetal bovine serum (Hyclone, Logan, UT, USA).

\section{Expression Vector Construction}

IP10-CDR3scfv gene and IP10-CDR3-PE40scfv gene were synthesized and restriction sites of HindIII and EcoRI were included. Their gene sequences were shown in the supple mentary material. They were then cloned to pcDNA3.1(+) vector, respectively, and transformed into E. coli DH5 $\alpha$. The plasmids were extracted using Endo-free plasmid mini kit II according to the manufacturer's manual and incubated in the buffer containing HindIII (10U) and EcoRI (10U) at $37^{\circ} \mathrm{C}$ for $1 \mathrm{hr}$. Eventually, the mixture was examined on a $1 \%$ agarose gel electrophoresis.

\section{Flow Cytometry}

IP10-CDR3scfv protein and IP10-CDR3-PE40scfv protein were labeled with FITC by FITC quick labeling kit according to the manufacturer's manual. In brief, the proteins in labeling buffer $(2 \mathrm{mg} / \mathrm{mL})$ were incubated in $12 \mu \mathrm{L}$ FITC at $37^{\circ} \mathrm{C}$ for 60 mins in the dark. After FITC clearance buffer $(1.5 \mu \mathrm{L})$ was added, the mixture was centrifuged at $12,000 \mathrm{~g}$ 
for 10 mins. The pellet was resuspended in appropriate amount of labeling buffer and then centrifuged at $12,000 \mathrm{~g}$ for $10 \mathrm{~min}$ again. This was repeated several times until there was no blue in the ultrafiltration tube. The pellet was resuspended in $0.2-0.5 \mathrm{~mL}$ preservation buffer to obtain FITClabeled proteins. FITC-labeled IP10-CDR3scfv protein and FITC-labeled IP10-CDR3-PE40scfv protein were added in the cells for $48 \mathrm{hrs}$. Six groups were formed: (1) SKOV3, (2) SKOV3+IP10-CDR3scfv, (3) SKOV3+IP10-CDR3PE40scfv, (4) HOSEpiC, (5) HOSEpiC+IP10-CDR3scfv, (6) HOSEpiC+IP10-CDR3-PE40scfv. Consequently, the cells were examined on a flow cytometer (NovoCyte 2060R, Acea Biosciences, China).

\section{Cell Transfection}

The plasmids were diluted in Opti-MEM and P3000 was added to prepare plasmid mixture which was incubated at room temperature for $5 \mathrm{mins}$ in the dark. Lipofectamine 3000 reagent was diluted in Opti-MEM and the mixture was incubated at room temperature for $5 \mathrm{~min}$ in the dark as well. Then, the plasmids were mixed with Lipofectamine 3000 reagent at room temperature for 15 mins in the dark. When cells reached $80 \%$ confluence, the plasmid-liposome mixture was added in serum-free medium. After culturing at $37^{\circ} \mathrm{C}$ and $5 \% \mathrm{CO}_{2}$ for $4 \mathrm{hrs}$, culture medium was changed to fresh complete medium containing serum and the cells were cultured for another $48 \mathrm{hrs}$.

\section{Experimental Grouping}

Cells were divided into four groups: Control (without any transfection), pcDNA3.1(+) negative control (NC) (pcDNA3.1(+) NC transfection), IP10-CDR3scfv (IP10CDR3scfv transfection) and IP10-CDR3-PE40scfv (IP10CDR3-PE40scfv transfection). Then levels of IP10, CDR3, Caspase-3, cleaved Caspase-3 and Bcl-2 were determined by RT-PCR and Western blot. Cell viability and apoptosis were investigated by CCK- 8 assay and Annexin V- FITC/PI assay, respectively.

\section{RT-PCR}

Total RNA of cells was extracted by Trizon reagent and reversely transcribed to cDNA by HiFiScript cDNA synthesis kit following the manufacturer's manuals. Sequences of primers are shown in Table 1. Reaction system $(20 \mu \mathrm{L})$ included $2 \mu \mathrm{L}$ cDNA, $0.4 \mu \mathrm{L}$ forward primer $(10 \mu \mathrm{M}), 0.4$ $\mu \mathrm{L}$ reverse primer $(10 \mu \mathrm{M}), 10 \mu \mathrm{L}$ ULtraSYBR Mixture and $7.2 \mu \mathrm{L}$ RNase free $\mathrm{ddH}_{2} \mathrm{O}$. Reaction parameters included pre-denaturation at $95^{\circ} \mathrm{C}$ for 10 mins, denaturation at $95^{\circ} \mathrm{C}$
Table I PCR Primers

\begin{tabular}{|l|l|}
\hline Primers & Sequences \\
\hline IPI0 & $\begin{array}{l}\text { For: GATTTGCTGCCTTATCTTTCTG } \\
\text { Rev: CTTTCCTTGCTAACTGCTTTCA }\end{array}$ \\
\hline CDR3 & $\begin{array}{l}\text { For: CCAAACCTAACATTCTCAACTCTG } \\
\text { Rev: AACTGCTCATTGCCCTCCC }\end{array}$ \\
\hline Caspase-3 & $\begin{array}{l}\text { For: TCTTTGAGTTCGGTGGGG } \\
\text { Rev: GCACAAAGCGACTGGATGAA }\end{array}$ \\
\hline BcI-2 & $\begin{array}{l}\text { For: TCTTTGAGTTCGGTGGGG } \\
\text { Rev: CACTTGTGGCTCAGATAGGC }\end{array}$ \\
\hline GAPDH & $\begin{array}{l}\text { For: GAAGGTCGGAGTCAACGGAT } \\
\text { Rev: CCTGGAAGATGGTGATGGG }\end{array}$ \\
\hline
\end{tabular}

for $5 \mathrm{~s}$, annealing at $60^{\circ} \mathrm{C}$ for $1 \mathrm{~min}$ and elongation at $72^{\circ} \mathrm{C}$ for $30 \mathrm{~s}$ (40 circles). Analysis parameters of dissociation curve were as follows: $15 \mathrm{~s}$ at $95^{\circ} \mathrm{C}, 1 \mathrm{~min}$ at $60^{\circ} \mathrm{C}, 15 \mathrm{~s}$ at $95^{\circ} \mathrm{C}, 15 \mathrm{~s}$ at $60^{\circ} \mathrm{C}, 15 \mathrm{~s}$ at $60^{\circ} \mathrm{C}$, and measured stepwise from $95^{\circ} \mathrm{C}$, every $0.5^{\circ} \mathrm{C}$. Products were examined on a RT-PCR system (CFX Connect, Bio-Rad, USA). Relative mRNA level of genes was calculated according to the $2^{-\Delta \Delta C t}$ method.14 GAPDH served as internal control.

\section{Western Blot}

Cells were lysed in RIPA buffer in an ice bath for 30 mins. The lysate was centrifuged at $4^{\circ} \mathrm{C}$ and $10,000 \mathrm{rpm}$ for 10 mins and the supernatant was collected carefully to obtain total protein. Protein concentration was determined by BCA kit. Thereafter, the protein was boiled. Protein (30 $\mu \mathrm{g})$ was loaded to conduct SDS-PAGE and transferred to PVDF membrane by a wet process. The membrane was incubated subsequently in primary antibodies buffer at $4{ }^{\circ} \mathrm{C}$ overnight, washed and incubated in secondary antibodies buffer at room temperature for $2 \mathrm{hrs}$. The protein blots were visualized by enhanced chemiluminescence reagent on a gel imaging system (ChemiDoc XRS+, Bio-Rad, USA). Gray values were analyzed using Quantity One software (v4.62, Bio-Rad, USA). GAPDH served as internal control.

\section{Cell Viability}

Cells were seeded into 96-well plate at a density of $1 \times 10^{4}$ per well and cultured at $37^{\circ} \mathrm{C}$ and $5 \% \mathrm{CO}_{2}$ for $48 \mathrm{hrs}$. CCK 8 reagent $(10 \mu \mathrm{L})$ was added into each well and cells were cultured for another 2 hrs. Absorbance was measured at $450 \mathrm{~nm}$ on a microplate reader (RT-6100, Rayto, USA). 


\section{Cell Apoptosis}

Cells were collected and treated with Annexin V-FITC/PI apoptosis kit according to the manufacturer's manual. In brief, cells were resuspended in $500 \mu \mathrm{L} 1 \times$ binding buffer and then incubated with $5 \mu \mathrm{L}$ Annexin V-FITC and $10 \mu \mathrm{L}$ PI at room temperature for 5 mins in the dark. Cells were analyzed immediately on a flow cytometer (NovoCyte 2060R, Acea Biosciences, China).

\section{Statistical Analysis}

Quantitative data were presented as mean \pm standard deviation. Statistical analysis was performed using one-way analysis of variance (ANOVA) followed by Tukey post-hoc test through SPSS software (v19.0, SPSS Inc., USA). Significant difference was recognized when $P$ value was less than 0.05 .

\section{Results}

\section{Expression Vector Construction}

Electrophorograms of pcDNA3.1-IP10-CDR3scfv (Figure 1A) and pcDNA3.1-IP10-CDR3-PE40scfv (Figure 1B) plasmids are shown in Figure 1. After pcDNA3.1-IP10-CDR3scfv plasmid was digested by HindIII/EcoRI, there should be $5428 \mathrm{bp}$ and 1552 bp bands in theory. After pcDNA3.1-IP10-CDR3PE40scfv plasmid was digested by HindIII/EcoRI, there should be 5428 bp and 2680 bp bands in theory. In Figure 1, the electrophoresis bands of pcDNA3.1-IP10-CDR3scfv plasmid and pcDNA3.1-IP10-CDR3-PE40scfv plasmid were consistent with the theoretical ones. These results proved that they were correct plasmids.

\section{Levels Of FITC-Labeled Proteins}

As shown in Figure 2, after the two FITC-labeled proteins were added to SKOV3 cells and HOSEpiC cells, the protein levels were determined by flow cytometry. The protein levels in the SKOV3+IP10-CDR3scfv group and the SKOV3+IP10CDR3-PE40scfv group were remarkably higher than that in the SKOV3 group $(\mathrm{P}<0.05)$. The protein levels in the HOSEpiC+IP10-CDR3scfv group and the HOSEpiC+IP10CDR3-PE40scfv group were also much higher than that in the HOSEpiC group $(\mathrm{P}<0.05)$. Moreover, compared with the SKOV3+IP10-CDR3scfv and HOSEpiC+IP10-CDR3scfv groups, the protein levels were significantly up-regulated in the SKOV3+IP10-CDR3-PE40scfv and HOSEpiC+IP10CDR3-PE40scfv groups, respectively $(\mathrm{P}<0.05)$.

\section{mRNA Levels Of IPI0, CDR3, Caspase-3 And $\mathrm{Bcl}-2$}

mRNA levels of IP10, CDR3, Caspase-3 and Bcl-2 in SKOV3 cells of various groups were determined by RTPCR (Figure 3). There was no obvious difference in their

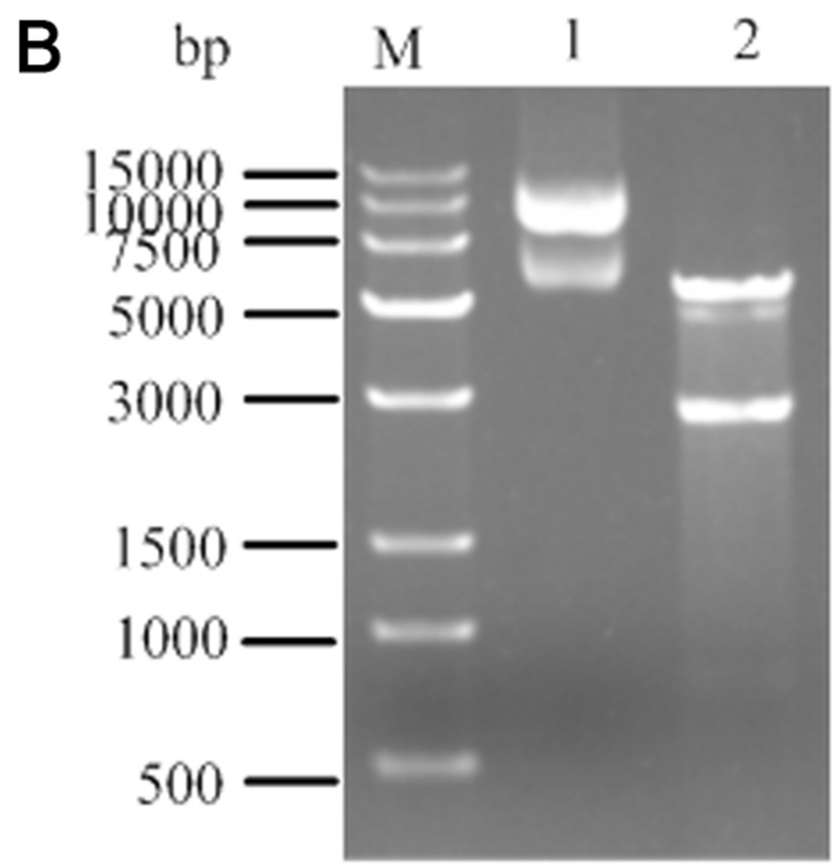

Figure I Electrophorograms of pcDNA3.I-IPI0-CDR3scfv (A) and pcDNA3.I-IPI0-CDR3-PE40scfv (B) plasmids. Lane I: pcDNA3.I-IPI0-CDR3scfv plasmid or pcDNA3.I-IPI0-CDR3-PE40scfv plasmid; Lane 2: pcDNA3.I-IPI0-CDR3scfv plasmid or pcDNA3.I-IPI0-CDR3-PE40scfv plasmid digested by HindIII/EcoRI. Abbreviation: $M$, marker 

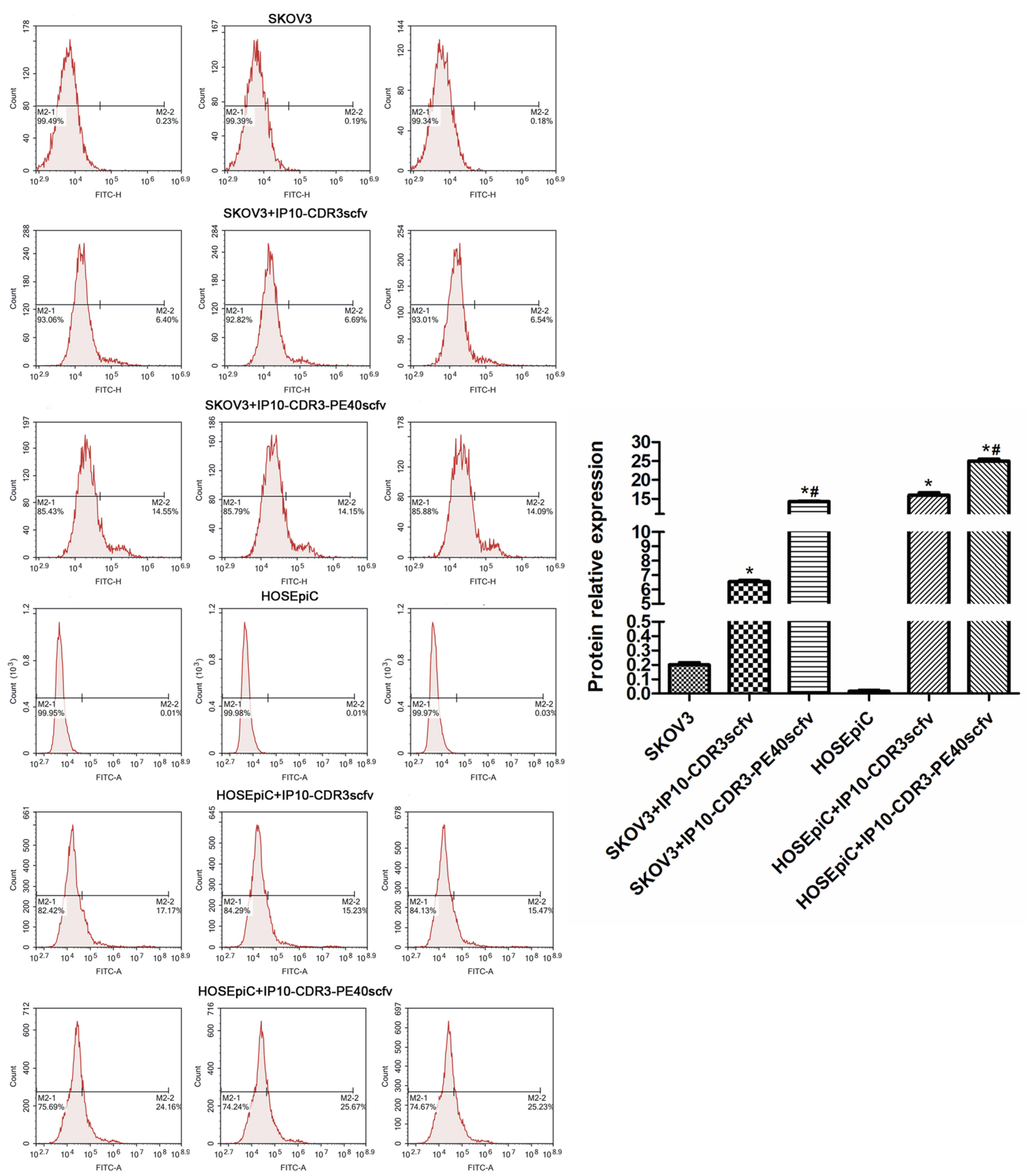

Figure 2 The protein levels after FITC-labeled IPIO-CDR3scfv protein and FITC-labeled IPI0-CDR3-PE40scfv protein were added to SKOV3 cells and HOSEpiC cells for 48 hrs which were determined by flow cytometry. ${ }^{* P}<0.05$ vs. SKOV3 or HOSEpiC; ${ }^{\# P<0.05 ~ v s . ~ S K O V 3+I P I 0-C D R 3 s c f v ~ o r ~ H O S E p i C+I P I 0-C D R 3 s c f v . ~}$

levels between the control group and the pcDNA3.1(+) NC group. However, compared with the control group, the mRNA levels of Caspase- 3 and Bcl-2 were reduced notably and the mRNA levels of IP10 and CDR3 were elevated sharply in the IP10-CDR3scfv and IP10-CDR3-PE40scfv groups $(\mathrm{P}<0.05)$. Moreover, compared with the IP10CDR3scfv group, the mRNA level of IP10 was reduced significantly in the IP10-CDR3-PE40scfv group $(\mathrm{P}<0.05)$. 


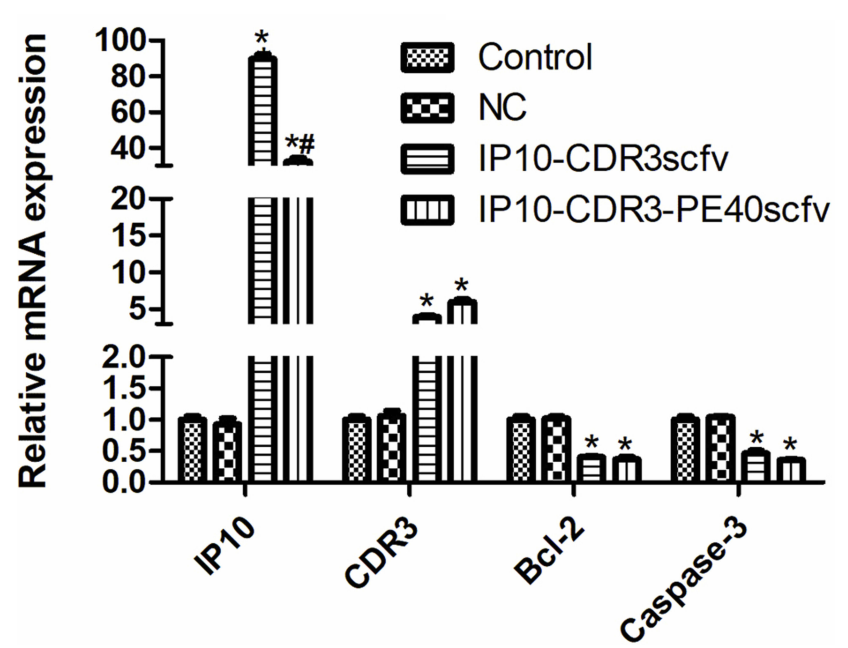

Figure 3 The mRNA levels of IPI0, CDR3, Caspase-3 and Bcl-2 in SKOV3 cells of various groups which were determined by RT-PCR. ${ }^{*} P<0.05$ vs. Control; ${ }^{\#} \mathrm{P}<0.05$ vs. IPI0-CDR3scfv. Control: without any transfection; NC: pcDNA3. I (+) negative control transfection.

\section{Protein Levels Of Caspase-3, Cleaved Caspase-3 And $\mathrm{Bcl}-2$}

Protein levels of Caspase- 3 and Bcl-2 in SKOV3 cells of various groups were evaluated by Western blot (Figure 4A).

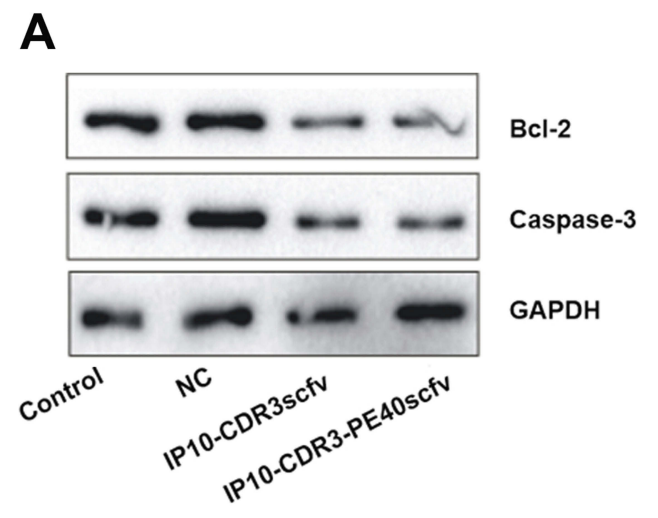

B

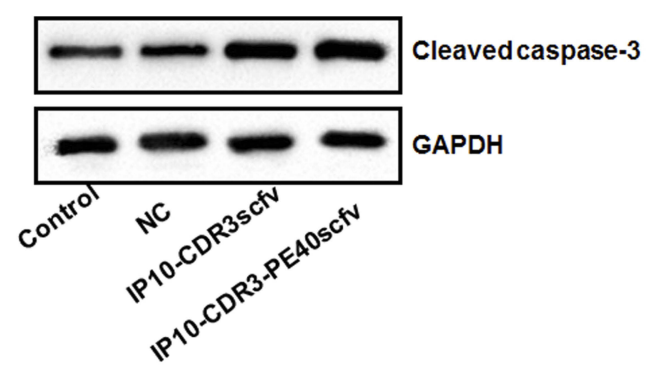

The control group and the pcDNA3.1(+) NC group demonstrated similar levels of Caspase-3 and Bcl-2. However, the IP10-CDR3scfv and IP10-CDR3-PE40scfv groups had much lower levels of Caspase-3 and Bcl-2 than the control group $(\mathrm{P}<0.05)$.

Protein levels of cleaved Caspase-3 in SKOV3 cells of various groups were also evaluated by Western blot (Figure 4B). The control group and the pcDNA3.1(+) NC group demonstrated similar levels of cleaved Caspase-3. However, the IP10-CDR3scfv and IP10-CDR3-PE40scfv groups had much higher levels of cleaved Caspase-3 than the control group $(\mathrm{P}<0.05)$.

\section{Cell Viability}

The viability of SKOV3 cells in various groups was examined by CCK-8 assay (Figure 5). The control group and the pcDNA3.1(+) NC group demonstrated similar cell viability. However, cell viability in the IP10-CDR $3 \mathrm{scfv}$ and IP10-CDR3-PE40scfv groups declined significantly compared with the control group $(\mathrm{P}<0.05)$. Moreover, compared with the IP10-CDR3scfv group, the cell
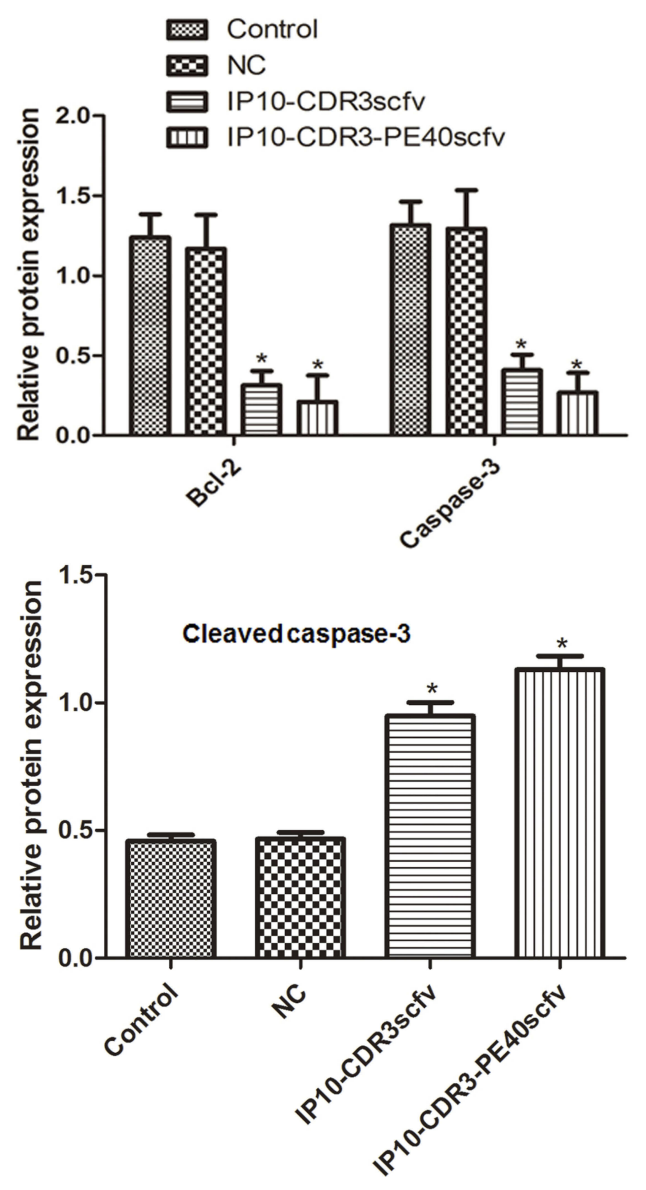

Figure 4 The protein levels of Caspase-3, Bcl-2 (A) and cleaved Caspase-3 (B) in SKOV3 cells of various groups which were evaluated by Western blot. *P $<0.05$ vs. Control. Control: without any transfection; NC: pcDNA3.I (+) negative control transfection. 


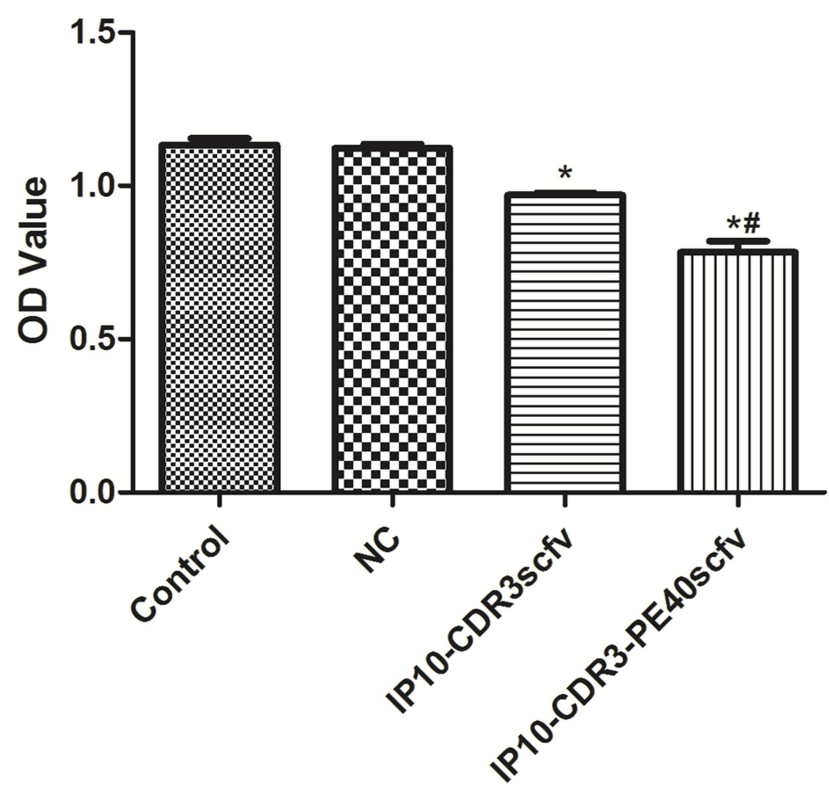

Figure 5 The viability of SKOV3 cells in various groups which was expressed as absorbance and examined by CCK-8 assay. ${ }^{* P}<0.05$ vs. Control; ${ }^{*} \mathrm{P}<0.05$ vs. IPI0CDR3scfv. Control: without any transfection; NC: pcDNA3.I(+) negative control transfection.

viability was reduced significantly in the IP10-CDR3PE40scfv group $(\mathrm{P}<0.05)$.

\section{Cell Apoptosis}

The apoptosis of SKOV3 cells in various groups was assessed by Annexin V-FITC/PI assay (Figure 6). The apoptotic ratio was similar between the control group and the pcDNA3.1(+) NC group. However, the apoptotic ratios in the IP10-CDR3scfv and IP10-CDR3-PE40scfv groups were significantly higher than that in the control group $(\mathrm{P}<0.05)$. Moreover, compared with the IP10CDR3scfv group, the apoptotic ratio was elevated significantly in the IP10-CDR3-PE40scfv group $(\mathrm{P}<0.05)$.

\section{Discussion}

Tumors can evade the supervision of immune system through a variety of mechanisms such as induction of $\mathrm{T}$ cell anergy, promotion of $\mathrm{T}$ cell apoptosis and inactivation of $\mathrm{T}$ cells. $\mathrm{T}$ cells are major effector cells involved in specific immune response and can participate in immune response through TCR. ${ }^{5-7}$ Proliferation and differentiation of $\mathrm{T}$ cells to immune cells need both antigen signals provided by TCR and synergistic signals.

Chemokines are cytokines produced by tumor cells, immune cells and some non-immune cells. They can act as a synergistic factor to promote $\mathrm{T}$ cell activation and break down the immune tolerance of tumors. ${ }^{9}$ They have chemotaxis and activation effects on monocytes, lymphocytes and neutrophils. ${ }^{15,16}$ Chemokines are highly homologous and can be classified into $\mathrm{C}, \mathrm{CC}, \mathrm{CXC}$ and $\mathrm{CX} 3 \mathrm{C}$ subtypes. IP10 is a chemokine screened from U937 cells and it is also named CXCL10. ${ }^{17}$ IP10 mainly comes from activated mononuclear macrophages, endothelial cells, fibroblasts and various lymphocytes. Its strong chemotaxis and activation effects on T cells, B cells, NK cells and dendritic cells promote the secretion of various cytokines and inhibit tumor growth. ${ }^{10-13}$ CXCR9 is the only receptor of IP10 and mediates the special function of IP10. It is located on human X chromosome and contains seven transmembrane proteins and three $\mathrm{N}$ glycosylation sites. Dendritic cells induced by IFN- $\gamma$ can promote the expression of IP10 and then the over-expression of IP10 facilitates the chemotaxis and activation of CD8+T cells which play an important role in anti-cancer activity. ${ }^{18,19}$

SKOV3 is human ovarian cancer cell line and HOSEpiC is human normal ovarian cell line. HOSEpiC and SKOV3 cells were used to confirm that IP10CDR3scfv and IP10-CDR3-PE40scfv could successfully enter normal ovarian cells and ovarian cancer cells. However, ovarian cancer cells are the cells of interest in this study, so only SKOV3 cells are used for the following assays. In this study, the IP10-CDR3scfv and IP10-CDR3PE40scfv genes were constructed and transfected into ovarian cancer cells. The results of restriction enzyme digestion assay proved the successful construction of the over-expressing vectors of IP10-CDR3scfv and IP10CDR3-PE40scfv. The examination of the levels of FITClabeled proteins by flow cytometry and the determination of IP10 and CDR3 levels by RT-PCR validated the overexpression of the two proteins in ovarian cancer cells. Subsequently, CCK-8 assay and Annexin V-FITC/PI assay were employed to explore the effects of IP10CDR3 on the viability and apoptosis of ovarian cancer cells. The results showed that IP10-CDR3scFv and especial IP10-CDR3-PE40scFv were able to greatly inhibit the proliferation and promote the apoptosis of ovarian cancer cells. These results indicated that IP10 could activate immune response of tumor cells and inhibit tumor cells growth.

Cell apoptosis is regulated by apoptosis-related genes. Bcl-2 is an oncogene found in follicular lymphocytes. It can form heterodimer with Bax and Bak, block the transmission of apoptotic signals to Caspase family and promote cell survival. ${ }^{20,21}$ Caspase-3 is the apoptosis executor of Caspase family. It is inactive under normal physiological conditions. After being stimulated by upstream signals, it is cleaved, 

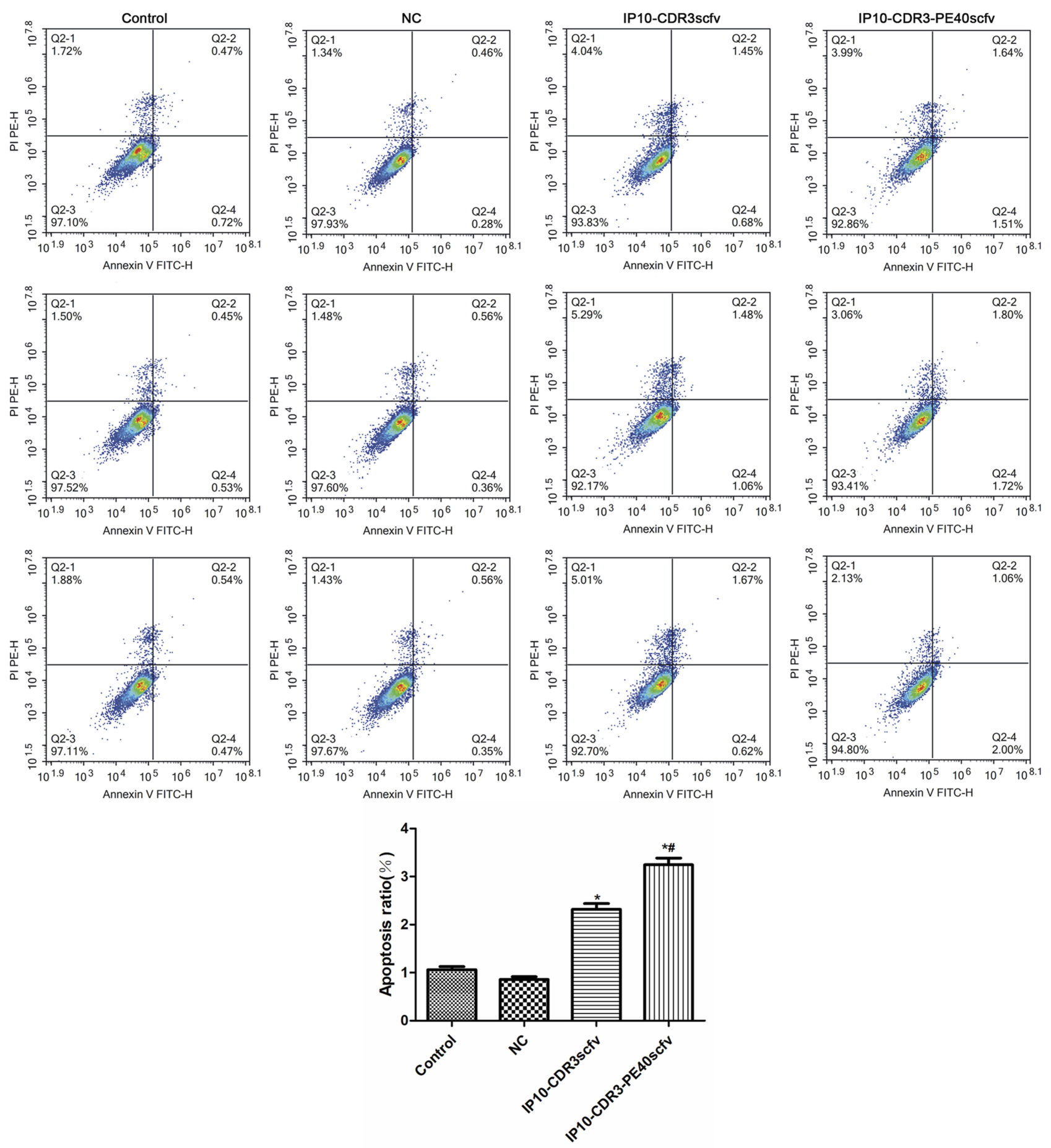

Figure 6 The apoptosis of SKOV3 cells in various groups which was assessed by Annexin V-FITC/PI assay. ${ }^{* P}<0.05$ vs Control; ${ }^{*} \mathrm{P}<0.05$ vs IPI0-CDR3scfv. Control: without any transfection; NC: pcDNA3.I(+) negative control transfection.

activated, breaks DNA and damages mitochondria. ${ }^{20,21}$ Previous studies have revealed that $\mathrm{Bcl}-2$ is over-expressed and Caspase-3 activity is increased in cancer tissues such as ovarian cancer, whereas after blocking these processes, apoptosis of ovarian cancer cells can be promoted. ${ }^{20-22}$ The transfection of IP10 gene into adipose-derived stem cells can significantly down-regulate the expression of $\mathrm{Bcl}-2 .{ }^{23}$ In this study, we investigated the levels of Bcl-2 and Caspase3 in SKOV3 cells of various groups by RT-PCR and Western blot and investigated the levels of cleaved Caspase- 3 by 
Western blot. The results showed that IP10-CDR3scfv and IP10-CDR3-PE40scfv significantly down-regulated the expression of Bcl-2 and Caspase-3 and up-regulated the level of cleaved Caspase-3. Therefore, IP10-CDR3 could induce the apoptosis of ovarian cancer cells by down-regulating the expression of Bcl-2 and Caspase-3.

\section{Conclusion}

We successfully constructed IP10-CDR3scfv and IP10CDR3-PE40scfv elements and revealed that IP10-CDR3 could reduce the viability and induce the apoptosis of ovarian cancer cells in vitro by down-regulating the expression of Bcl-2 and Caspase-3. Although these results should be further verified by more in vitro and in vivo experiments, they might still provide useful theoretical guidance for ovarian cancer-related treatment and drug development.

\section{Acknowledgments}

The present study was supported by the National Natural Science Foundation of China (No. 81560247), the Jiangxi Provincial Science and Technology Pillar Program (No. 20151BBG70072) and the Science and Technology Research Program of Jiangxi Provincial Education Commission (No. GJJ10339).

\section{Disclosure}

The authors report no conflicts of interest in this work.

\section{References}

1. Crane EK, Brown J. Early stage mucinous ovarian cancer: a review. Gynecol Oncol. 2018;149:598-604. doi:10.1016/j.ygyno.2018.01.035

2. Qin M, Jin Y, Ma L, et al. The role of neoadjuvant chemotherapy followed by interval debulking surgery in advanced ovarian cancer: a systematic review and meta-analysis of randomized controlled trials and observational studies. Oncotarget. 2018;9:8614-8628. doi:10. 18632/oncotarget.v9i9

3. Vetter MH, Hays JL. Use of targeted therapeutics in epithelial ovarian cancer: a review of current literature and future directions. Clin Ther. 2018;40:361-371. doi:10.1016/j.clinthera.2018.01.012

4. Bray F, Ferlay J, Soerjomataram I, et al. Global cancer statistics 2018: GLOBOCAN estimates of incidence and mortality worldwide for 36 cancers in 185 countries. CA Cancer J Clin. 2018;68:394-424. doi:10.3322/caac.v68.6

5. Alipour S, Zoghi S, Khalili N, et al. Specific immunotherapy in ovarian cancer: a systematic review. Immunotherapy. 2016;8:11931204. doi:10.2217/imt-2016-0034

6. Odunsi K. Immunotherapy in ovarian cancer. Ann Oncol. 2017;28:i1i7. doi:10.1093/annonc/mdx444
7. Genta S, Ghisoni E, Giannone G, et al. Reprogramming T-cells for adoptive immunotherapy of ovarian cancer. Expert Opin Biol Ther. 2018;18:359-367. doi:10.1080/14712598.2018.1425679

8. Luo W, Zhang XB, Huang YT, et al. Development of genetically engineered CD4+ and CD8+ T cells expressing TCRs specific for a M. tuberculosis 38-kDa antigen. J Mol Med (Berl). 2011;89:903-913. doi:10.1007/s00109-011-0760-4

9. Wang X, Zhang FC, Zhao HY, et al. Human IP10-scFv and DCinduced CTL synergistically inhibit the growth of glioma in a xenograft model. Tumor Biol. 2014;35:7781-7791. doi:10.1007/s13277-0 14-1867-3

10. Santos VS, Goletti D, Kontogianni K, et al. Acute phase proteins and IP-10 as triage tests for the diagnosis of tuberculosis: systematic review and meta-analysis. Clin Microbiol Infect. 2019;25(169):177. doi:10.1016/j.cmi.2018.07.017

11. Chen LJ, Lv J, Wen XY, et al. CXC chemokine IP-10: a key actor in liver disease? Hepatol Int. 2013;7:798-804. doi:10.1007/s12072-0139445-0

12. Liu M, Guo S, Hibbert JM, et al. CXCL10/IP-10 in infectious diseases pathogenesis and potential therapeutic implications. Cytokine Growth Factor Rev. 2011;22:121-130. doi:10.1016/j.cytogfr.2011. 06.001

13. Taslimi Y, Zahedifard F, Habibzadeh S, et al. Antitumor effect of IP10 by using two different approaches: live delivery system and gene therapy. J Breast Cancer. 2016;19:34-44. doi:10.4048/jbc.2016. 19.1.34

14. Livak KJ, Schmittgen TD. Analysis of relative gene expression data using real-time quantitative PCR and the $2^{-\Delta \Delta C T}$ method. Methods. 2001;25:402-408. doi:10.1006/meth.2001.1262

15. Bhatt P, Kumaresan V, Palanisamy R, et al. A mini review on immune role of chemokines and its receptors in snakehead murrel channa striatus. Fish Shellfish Immunol. 2018;72:670-678. doi:10. 1016/j.fsi.2017.11.036

16. Zhang M, Zhu ZL, Gao XL, et al. Functions of chemokines in the perineural invasion of tumors (review). Int J Oncol. 2018;52:13691379.

17. Dufour JH, Dziejman M, Liu MT, et al. IFN- $\gamma$-inducible protein 10 (IP-10; CXCL10)-deficient mice reveal a role for IP-10 in effector T cell generation and trafficking. J Immunol. 2002;168:3195-3204. doi:10.4049/jimmunol.168.7.3195

18. Mohty AM, Grob JJ, Mohty M, et al. Induction of IP-10/CXCL10 secretion as an immunomodulatory effect of low-dose adjuvant interferon-alpha during treatment of melanoma. Immunobiology. 2010;215:113-123. doi:10.1016/j.imbio.2009.03.008

19. Fallahi P, Ragusa F. Mesothelioma and interferon-gamma-dependent chemokine IP-10. Clin Ter. 2016;167:e192-e197.

20. Ptak A, Rak-Mardyła A, Gregoraszczuk EL. Cooperation of bisphenol A and leptin in inhibition of caspase-3 expression and activity in OVCAR-3 ovarian cancer cells. Toxicol in Vitro. 2013;27:1937-1943. doi:10.1016/j.tiv.2013.06.017

21. Zhao X, Wang D, Zhao Z, et al. Caspase-3-dependent activation of calcium-independent phospholipase A2 enhances cell migration in non-apoptotic ovarian cancer cells. J Biol Chem. 2015;281:2935729368.

22. Shirali S, Aghaei M, Shabani M, et al. Adenosine induces cell cycle arrest and apoptosis via cyclinD1/Cdk4 and Bcl-2/Bax pathways in human ovarian cancer cell line OVCAR-3. Tumor Biol. 2013;34:1085-1095. doi:10.1007/s13277-013-0650-1

23. Mahboobeh R, Mansooreh J, Abbas G. Downregulation of MMP2 and Bcl-2 in Adipose Derived Stem Cells (ASCs) following transfection with IP-10 gene. Avicenna J Med Biotechnol. 2014;6:27-37. 


\section{Publish your work in this journal}

OncoTargets and Therapy is an international, peer-reviewed, open access journal focusing on the pathological basis of all cancers, potential targets for therapy and treatment protocols employed to improve the management of cancer patients. The journal also focuses on the impact of management programs and new therapeutic

Submit your manuscript here: https:/www.dovepress.com/oncotargets-and-therapy-journal agents and protocols on patient perspectives such as quality of life, adherence and satisfaction. The manuscript management system is completely online and includes a very quick and fair peer-review system, which is all easy to use. Visit http://www.dovepress.com/ testimonials.php to read real quotes from published authors. 